\title{
DIGITALCOMMONS
}

@WAYNESTATE —

Wayne State University

Kinesiology, Health and Sport Studies

College of Education

$1-1-2006$

\section{Psychosocial Aspects of Youth Disability Sport}

Jeffrey J. Martin

Wayne State University, aa3975@wayne.edu

\section{Recommended Citation}

Martin, J. J. (2006). Psychosocial aspects of youth disability sport. Adapted Physical Activity Quarterly, 23(1), 65-77. Available at: http://digitalcommons.wayne.edu/coe_khs/17

This Article is brought to you for free and open access by the College of Education at DigitalCommons@WayneState. It has been accepted for inclusion in Kinesiology, Health and Sport Studies by an authorized administrator of DigitalCommons@WayneState. 


\title{
Psychosocial Aspects of Youth Disability Sport
}

\author{
Jeffrey J. Martin \\ Wayne State University
}

\begin{abstract}
Psychosocial aspects of participation in youth disability sport were examined using social-cognitive theory and the sport commitment model. An international sample of athletes with disabilities $(N=112)$ reported high levels of sport commitment and sport enjoyment, perceived physical ability, and sport friendship quality. They perceived their parents to provide moderately strong levels of encouragement of their sport participation. Correlational analyses indicated moderate to strong relationships among sport commitment, sport enjoyment, and perceived physical ability. Sport commitment, parental encouragement, and sport friendship quality were only somewhat related. Regression analyses indicated that enjoyment was a significant predictor (i.e., $43 \%$ of the variance) of sport commitment. The sport experience was a positive one for these athletes and enjoyment is likely a critical motivational factor in promoting a continued desire to remain in sport.
\end{abstract}

Numerous scientists have examined important psychological and social aspects of children and youth involvement in sport and physical activity (Brustad, 1992; Weiss \& Smith, 1999; Weiss \& Stuntz, 2004). Unfortunately, similar research with children and youth with disabilities is rare, although research on physical activity in general and disability has been identified as a national priority (Rimmer \& Braddock, 1997; Rimmer, Braddock, \& Pitetti, 1996). Research examining disability specifically and physical activity is considered vital because many individuals with disabilities are often inactive, and the ramifications of being inactive exacerbate the detrimental effects of a disability for many people (Heath \& Fentem, 1997). Increased physical activity, such as that obtained through sport participation, can positively influence health related quality of life (Rejeski, Brawley, \& Shumaker, 1996). With appropriate adult involvement, youth sport can also be an effective vehicle for promoting psychological benefits such as enhanced self-esteem (Whitehead \& Corbin, 1997).

Thus, understanding involvement in sport by children with disabilities from a psychosocial perspective is the current study's primary purpose. The guiding theory for the current study was social cognitive theory (Bandura, 1997) and the sport commitment model (Scanlan, Carpenter, Simons, Schmidt, \& Keeler, 1993a). In brief, social cognitive theory posits that a variety of social, cognitive, and affective

The author is with the Division of Health, Physical Education, and Recreation at Wayne State University, Detroit, MI 48202. E-mail: aa3975@wayne.edu 
factors influence behavior. Social cognitive theory also acknowledges the important roles of both individual thought and social systems on human functioning (Bandura, 1997).

Specifically, I sought to understand the levels of, and relationships among, psychosocial constructs that researchers have identified as important to the youth sport experience (Weiss \& Stuntz, 2004). A second purpose was to simultaneously predict sport commitment. It is important to understand potential antecedents of sport commitment because sport commitment reflects the "desire to continue sport participation" (Scanlan et al., 1993a, p. 6). Thus, it provides an indication of continued involvement that is critical to achieving ongoing psychological and physiological benefits (Rejeski et al., 1996). In addition to predicting sport commitment, another goal was to examine important psychological and social factors that would provide valuable descriptive information about these children's sport experiences. As a result, I sought to measure broadly divergent social and psychological factors that would be theoretically and logically related to sport commitment and provide important information about the participants' sport experience.

To predict sport commitment, four psychosocial variables were assessed. Research by Scanlan and colleagues (Carpenter, Scanlan, Simons, \& Lobel, 1993; Scanlan et al., 1993a; Scanlan, Simons, Carpenter, Schmidt, \& Keeler, 1993b) on sport commitment was a logical starting point because it was developed for the youth sport domain. I chose sport enjoyment as a predictor of commitment because it is a primary determinant of sport commitment and has been strongly supported by research (Carpenter et al., 1993; Scanlan et al., 1993a, 1993b). Children who experience fun in sport are more likely to remain committed compared to children who do not find the sport experience a positive one. Importantly, enjoyment or fun has, independently of Scanlan's sport commitment research program (Carpenter et al., 1993; Scanlan et al., 1993a, 1993b), been shown to be an important motive for youth sport participation (Gill, Gross, \& Huddleston, 1985; Gould, Feltz, \& Weiss, 1985). Sport enjoyment reflects an affective versus a cognitive construct and can often result from nonachievement related aspects of the sport experience. Therefore, examining sport enjoyment was consistent with my research goal of examining a broad range of psychosocial cognitive and affective variables.

The second predictor of sport commitment was a common sport achievement cognition: namely, perceived physical ability. Many sport and exercise scientists have indicated that a critical psychological and achievement based determinant of sport participation is athletes' perceived competence (e.g., Harter, 1982; Marsh, 1987). In brief, children who possess an adequate sense of competence in their physical capabilities are likely to participate in sport and physical activity and be committed.

Children who have doubts about their physical ability tend to report weaker participation motivation. In brief, belief in one's physical capabilities is a primary achievement based determinant of motivated physical activity behavior (Brustad, 1993, 1996; Harter, 1982; (Eccles) Parsons, Adler, \& Kaczala, 1982). Furthermore, Weiss and Chaumeton (1992) have asserted that the primary distinguishing characteristic between youth sport participants and drop-outs is perceived competence.

The last two predictors of sport commitment examined were parental and peer related factors. I specifically chose these two social mechanisms of influence for two reasons. First, including potential social influences of sport commitment 
acknowledges the critical role that parents and peers play in youth sport (Brustad, 1996). As Brustad indicated in 1992, it is important to integrate socialization factors into research examining children's motivation. Second, varied research into peer relations (Chase \& Dummer, 1992; Evans \& Roberts, 1987) and friendship (Weiss \& Duncan, 1992; Weiss \& Smith, 1999) suggests there is value in investigating these constructs in youth sport. Finally, in contrast to investigations about perceived competence, limited research examining friendship and parental involvement in youth disability sport has been done. The current study seeks to help fill this void.

Brustad's $(1992,1993,1996)$ line of research has examined the role that parents play in promoting sport and physical activity. Parents, for example, who were encouraging of their children's physical activity participation raised children with stronger perceptions of their physical competence compared to children with less encouraging parents (Brustad, 1993). Parental affective responses (e.g., enjoyment of physical activity) also influenced children's propensity to engage in physical activity (Brustad, 1996). Parental involvement in youth sport for children with disabilities may be particularly important to assess because adolescents with physical disabilities rely on their parents for sport related support (Martin \& Mushett, 1996), and parents are often critical in helping their children develop physical activity self-efficacy (Mandich, Polatajko, \& Rodger, 2003). Finally, Nixon (1988) suggested that parents of children with disabilities worry about the potential for injury in physical activity and might be reluctant to encourage their children to play sport. To examine if parental involvement was related to sport commitment athletes' perceptions of parental encouragement were examined.

Finally, peer relations exert a major influence on youth psychosocial development and behavior (Sullivan, 1953). Research in the sport domain has been limited and has typically focused on peer acceptance, status, and popularity (Chase \& Dummer, 1992; Evans \& Roberts, 1987), with less research on friendship (Smith, 1999; Weiss \& Smith, 1999). However, this limited research indicates that competence in sport is linked to social status, popularity, and peer acceptance (Brustad, 1993; Chase \& Dummer, 1992; Evans \& Roberts, 1987; Weiss \& Duncan, 1992), and friendship is related to positive affect (e.g., enjoyment) in physical activity (Smith, 1999). It may be particularly important to examine peer relations in youth disability sport because children who are perceived to be different (e.g., have a physical disability) or seem to lack strong motor skills (e.g., developmental coordination disorder) may be at increased risk for peer rejection or neglect (Parker \& Asher, 1987; Schoemaker \& Kalverboer, 1994; Sigelman, Miller, \& Whitworth, 1986). For instance, poorly coordinated children perceived a lack of social acceptance from their peers compared to children who were well coordinated (Rose, Larkin, \& Berger, 1997). Finally, individuals with disabilities often have less extensive social networks and fewer friendships compared to nondisabled individuals (McNeil, 1993), making the sport setting a potentially attractive social opportunity for children who may desire stronger peer relations.

Being with friends by participating in sport is a primary motive for youth sport participation (Weiss \& Ferrer-Caja, 2002). Determining how youth feel about the quality of their relationship with their best friend in sport appears to be a plausible predictor of sport commitment. Therefore, based on Weiss and colleagues' line of research (Smith, 1999; Weiss \& Smith, 1999; Weiss, Smith, \& Theeboom, 1996), 
the quality of youth friendships in disability sport were examined. In summary, the current study is an important step toward providing vital psychosocial descriptive data about youth disability sport participants. Additionally, the present investigation allowed me to examine divergent social and psychological predictors of sport commitment. More specifically, it was hypothesized that sport enjoyment, perceptions of physical ability, sport friendship quality, and parental encouragement would be positively related to sport commitment.

\section{Method}

\section{Participants}

Youths $(N=112)$ participating in the Western Australia Disability Sport Association Swimming $(n=34)$ and Track and Field $(n=78)$ Championships participated in the current study. Male $(n=63)$ and female $(n=49)$ athletes from Australia $(n=$ $60)$, the USA $(n=27)$, South Africa $(n=23)$, and New Zealand $(n=2)$ participated. They ranged in age from 12 to 18 years $(M=15.33, S D=1.64)$. The age breakdown was skewed toward the older ages as follows: $12, \mathrm{n}=8 ; 13, \mathrm{n}=7 ; 14, \mathrm{n}=16 ; 15$, $\mathrm{n}=28 ; 16, \mathrm{n}=29 ; 17, \mathrm{n}=10 ; 18, \mathrm{n}=14$. Years of participating in disability sport was $(M=6.11, S D=3.42)$.

As the competition was not disability sport specific, athletes represented 5 disability types: spina bifida $(n=54)$, paraplegia $(n=18)$, cerebral palsy $(n=22)$, amputee $(n=8)$, and spinal cord injured $(n=10)$. There was also a wide range of severity of disability as determined by their sport classification categories that are indicative of their level of sport function (Dummer, 1999; Sherrill, 1997). For instance, the swimmers ranged from least functional to most functional as follows: $\mathrm{S} 1, \mathrm{~S} 2, \mathrm{~S} 3, \mathrm{~S} 4(n=0), \mathrm{S} 5(n=3), \mathrm{S} 6(n=6), \mathrm{S} 7(n=10), \mathrm{S} 8(n=12), \mathrm{S} 9(n=0)$, $\mathrm{S} 10(n=3)$ (Dummer, 1999). Thus, 31 of the 34 swimmers were classified as S6 and above which is indicative of "efficient arm movements, limited to good leg propulsion, good control of upper trunk, and an ability to catch water" (Dummer, 1999, p. 217). The track and field athletes' $(n=78)$ reported neurological level was quite diverse as follows: T4 $(n=12), \mathrm{T} 5(n=8), \mathrm{S} 1-\mathrm{S} 2(n=5), \mathrm{C} 7-\mathrm{C} 8(n=$ $5)$, T1-T7 $(n=7)$, T8-L1 $(n=2)$, T9 $(n=2)$, T10 $(n=1)$, L5 $(n=2)$ L2-5 $(n=3)$, T6 $(n=1), \mathrm{T} 3(n=1)$, and unreported $(n=24)$.

The international nature of the competition resulted in a heterogeneous sample of youth from four different countries. Although the age range (i.e., 12-18 years) might be considered large, it was skewed toward the older end and can be considered to capture the "adolescent" age range (Horn, 2004). Additionally, the measures described next are considered appropriate for ages 12 and up. For instance, both the sport enjoyment and sport commitment scales were developed and evaluated with a heterogeneously aged group to enhance their potential generalizability (Scanlan et al., 1993b)

\section{Measures}

Demographic Scale. Participants provided informed consent and completed a demographic scale indicating age, gender, and disability sport experience, disability type and classification, and citizenship. 
Sport Commitment. Children completed Scanlan et al.'s (1993b) 4 item sport commitment scale. Validity and reliability was established with similar aged $(M=$ 12.49) boys and girls $(N=178)$. Participants responded to 3 questions asking how dedicated and how determined they were to playing disability sport, and how hard it would be to quit disability sport. Respondents answered on a 1 to 5 point Likert scale with anchors of not at all dedicated/determined/hard and very dedicated/ determined/hard. The fourth question asked "what would you be willing to do to keep playing disability sport" with anchors of nothing at all and a lot of things. All 4 questions were modified by adding "disability" in front of "sport."

Sport Enjoyment. Athletes completed Scanlan et al's (1993b) 4-item sportenjoyment scale, asking if they enjoyed, had fun, were happy, and liked playing disability sport. Similar to sport commitment scale, the psychometric properties of the sport enjoyment scale were established with comparably aged $(M=12.49)$ boys and girls $(N=178)$. Participants responded on a 1 to 5 point Likert scale with anchors of not at all and very much. All 4 questions were modified by adding "disability" in front of "sport."

Parental Encouragement. Athletes reported their perceptions of parental encouragement by responding to Brustad's (1996) 6-question parental encouragement and support of physical activity and sport scale. Items were modified to reflect disability sport instead of physical activity. For example, participants were asked if their parents "encouraged their participation in disability sport." Athletes responded on a 1 to 5 point Likert scale with anchors of strongly disagree and of strongly agree.

Sport Friendship Quality Scale (SFQS). Participants completed the 22-item SFQS scale developed by Weiss and Smith (1999) to assess the quality of youth sport friendships and was developed specifically for youth sport. Youth responded to a 1 to 5 point Likert scale with anchors of not at all true and really true. The positive (e.g., we do fun things together) aspects of friendship were assessed with 19 items and the conflict (e.g., have arguments) aspects of friendships are assessed with 3 items. Greater detail on item content and the SFQS psychometric properties can be found in Martin and Smith (2002).

Perceived Physical Ability. Athlete's perceptions of their physical abilities was assessed with Marsh's (1990) physical abilities subscale of the self-description questionnaire (SDQ-I) designed for adolescents and youth. An example of two of the 5 questions that participants responded to were "I am good at sports" and "I am a good athlete." Anchors of false and true based on a 5 point likert scale followed each question. Questions referring to sport were modified by adding "disability" in front of "sport."

\section{Procedure}

Approval was first obtained from the university institutional review board to conduct the current study. Next, permission from the meet organizers and coaches (acting as parental proxies) to collect data at competition sites was obtained. The author and a student with a degree in adapted physical education then collected data at the swimming pool and athletic track two mornings prior to the start of athletes' 
competition, which spanned a weekend. Most athletes completed the entire set of instruments within 20 minutes.

Participants were urged to respond honestly and that there were no right or wrong answers. They were also told that their responses would be completely confidential (i.e., parents or coaches would not see their answers) and any written reports would be based on group data with no individual names revealed. Athletes who needed assistance because their disability (e.g., spasticity) made writing difficult had their answers were recorded for them.

\section{Results}

\section{Internal Consistency}

Alpha coefficients (Cronbach, 1951) for Sport Commitment $(\alpha=.85)$, Sport Enjoyment $(\alpha=.93)$, Physical Ability $(\alpha=.76)$, Positive Aspects of Friendship Quality ( $\alpha=.94)$, Conflict Aspects of Friendship Quality $(\alpha=.75)$, and Parental Encouragement ( $\alpha=.65$ ) scales were acceptable (Nunnally, 1978).

\section{Preliminary Analyses and Descriptive Results}

Four ANOVA's were conducted to determine if athletes differed on the six psychological variables according to age, gender, country, or disability type in order to justify collapsing data. First, for age there was one significant difference for Sport Commitment: $F(6,105)=2.42, p<.03$, partial eta squared $=.12$. Post hoc results suggested that the 17-year-old athletes expressed less commitment $(M=$ 3.60, $S D=1.12$ ) compared to the other age groups who all ranged from 4.2 to 4.5. Second, for gender, $F(1,110)=11.71, p<.001$, partial eta squared $=.10$, there was one significant difference as girls reported a higher $(M=4.00, S D=.61)$ mean for positive aspects of quality of sport friendship compared to the boys $(M=3.47$, $S D=.88)$. Third, for country, $F(3,108)=3.36, p<.05$, partial eta squared $=.09$, there was one significant difference for Perceptions of Physical Ability. Post hoc results indicated that athletes from South Africa $(M=4.14, S D=.63)$ had slightly weaker perceptions of their physical ability compared to Australia $(M=4.43, S D$ $=.49)$ and the USA $(M=4.63, S D=.59)$. Last, for disability type there were no significant differences.

The effect sizes (i.e., partial eta squared) for the 3 differences ranged from .09 to .12. and are considered to fall between medium and large (Cohen, 1988) despite accounting only for approximately $10 \%$ of the variance. Given the overall pattern of a lack of significant differences across the 6 dependent variables and the 4 independent variables, it was considered justifiable to collapse the data across all groupings.

Table 1 contains the means, standard deviations, ranges, skewness, and kurtosis for all variables and all participants. Athletes reported quite positive perceptions as all of the means were quite high ( $M$ 's $=4.30$ - 4.60) with the exception of friendship quality $(M=3.69-3.93)$, which was still well above neutral. 


\section{Correlational and Regression Results}

Table 2 illustrates the correlations among all variables and indicates fairly strong relationships among sport commitment, sport enjoyment, and perceptions of physical ability. Statistically significant but small correlations exist between parental encouragement and sport commitment and between positive aspects of sport friendship and sport commitment. Sport commitment was unrelated to conflict aspects of friendship. Table 3 provides the regression results with all 5 predictor variables of sport commitment entered. Sport enjoyment was a substantial predictor of sport commitment. Multicollinearity among the predictor variables did not exist, based on the variance inflation factors, tolerance figures, and the bivariate correlation between two predictor variables $(r=$ or $>.90)$ cited by Tabachnick and Fidell (1989, p. 87).

Table 1 Means, Standard Deviations, Ranges, Skewness, and Kurtosis for all Variables

\begin{tabular}{lccccc}
\hline Variable & $M$ & $S D$ & Range & Skewness & Kurtosis \\
\hline Sport Commitment & 4.38 & .75 & 3.0 & -1.44 & 1.47 \\
Sport Enjoyment & 4.60 & .68 & 3.5 & -1.92 & 3.76 \\
Perceptions of & 4.42 & .57 & 2.2 & -.95 & .42 \\
$\quad$ Physical Ability & 4.30 & .58 & 3.2 & -1.17 & 2.1 \\
Parental Encouragement & 3.69 & .81 & 4.0 & -.80 & .51 \\
Positive Friendship & 3.93 & .95 & 4.0 & -.58 & -.44 \\
Conflict Friendship & & & & & \\
\hline
\end{tabular}

\section{Table 2 Variable Correlations}

\begin{tabular}{lccccc}
\hline & 1 & 2 & 3 & 4 & 5 \\
\hline $\begin{array}{l}\text { Sport Commitment } \\
\text { Sport Enjoyment }\end{array}$ & $.66^{* *}$ & & & & \\
$\begin{array}{l}\text { Perceptions of } \\
\text { Physical Ability }\end{array}$ & $.45^{* *}$ & $.55^{* *}$ & & & \\
Parental Encouragement & $.21^{*}$ & $.31^{* *}$ & $.27^{* *}$ & & \\
Positive Friendship & $.27^{* *}$ & $.21^{*}$ & .12 & .05 & \\
Conflict Friendship & .00 & .03 & .12 & .06 & -.07 \\
\hline
\end{tabular}

Note. $* p<.05, * * p<.01$ 
Table 3 Multiple Regression Results

\begin{tabular}{clccccccc}
\hline Step & Variable & $\mathbf{R}^{2}$ & $\mathrm{~F}$ & $d f$ & $p<$ & $\Delta \mathbf{R}^{2}$ & $\begin{array}{c}\beta \\
\text { at entry }\end{array}$ & $\begin{array}{c}p \\
\text { at entry }\end{array}$ \\
\hline 1 & EN & .43 & 83.76 & 1,110 & .001 & .43 & .56 & .001 \\
2 & PPA & .44 & 43.41 & 2,109 & .001 & .01 & .13 & .140 \\
3 & PFR & .46 & 30.77 & 3,108 & .001 & .02 & .13 & .069 \\
4 & CFR & .46 & 22.91 & 4,107 & .001 & .02 & -.02 & .760 \\
5 & PE & .46 & 18.16 & 5,106 & .001 & .00 & -.01 & .940 \\
\hline
\end{tabular}

Note. EN $=$ Sport enjoyment PPA = Perceptions of physical ability; PFR = Positive Aspects of Friendship; $\mathrm{CFR}=$ Conflict Aspects of Friendship; $\mathrm{PE}=$ Parental encouragement

\section{Discussion}

The purpose of the current study was to describe psychosocial perceptions of youth athletes with disabilities, which would provide a glimpse into how they viewed their sport experience. Additionally, I sought to simultaneously examine psychological and social predictors of their commitment to sport.

The descriptive results indicated that athletes were quite committed to and enjoyed their sport experience. Additionally, they had strong feelings about their physical abilities and perceived that their parents were very supportive of their participation in sport. Finally, although they viewed the quality of their friendship in sport as positive, they were slightly less favorable in their assessments of their friendship quality compared to assessments of the other variables (e.g., enjoyment). These results are encouraging as they indicate that the sport experience was a positive one. For instance, athletes reported liking, enjoying, and having fun in sport and that they were determined to continue participating in the future.

As importantly, participants reported feeling physically capable. It is plausible that athletes made physical competence inferences based on other competitors with similar disabilities. The process by which individuals use a frame of reference established by significant others (e.g., peers on their team, other competitors) to make self-concept and competence assessments has been referred to as the Big Fish Little Pond Effect (BFLPE) by Marsh (1998). Although research support for this phenomenon seems stronger in academic studies (Marsh, 1987), investigations with athletes and physical self-concept are supportive of the BFLPE (Marsh, 1987, 1993, 1998; Marsh \& Peart, 1988; Marsh, Perry, Horsely, \& Roche, 1995).

Athletes also reported high levels of parental encouragement. This finding is somewhat notable because there is some evidence to suggest that parents may not encourage their children to be physically active because they are worried about injury (Nixon, 1988). Children in Nixon's study had vision loss, pointing to the potential influence of disability type on parental worry and subsequent encouragement. Wang and DePauw (1995) have reported that although few parents (i.e., 27\%) of children participated in sport, many (i.e., $80 \%$ ) were still encouraging of their children's sport participation. The present study adds additional support to Wang and DePauw's (1995) findings, which were based on Chinese participants. 
The ANOVA results indicated that parental encouragement did not vary according to gender. Most sport sociologists and psychologists have recognized that sport has historically been viewed as a male domain (e.g., Messner, 1992). As a result of the pervasiveness of this belief, boys are often thought to receive more encouragement and reinforcement to play sport. For instance, Eccles and Harold (1991) have found that boys believed that their parents thought it was more important that they succeeded in sport than it was for the girls to succeed in sport. Thus, it is encouraging that in the current study, males and females reported high and equitable amounts of parental encouragement.

A major purpose of the current investigation was to examine whether sport enjoyment, perceived physical ability, sport friendship quality, and parental encouragement helped to predict athletes' commitment to sport. Correlational analyses determined that moderately strong relationships existed between sport enjoyment and sport commitment and between perceptions of physical ability and sport commitment ( $r=.66$ and .45 , respectively). Although statistically significant, the correlation between parental encouragement and sport commitment $(r=.21)$ was small as was the relationship between positive aspects of friendship and sport commitment $(r=.27)$. Thus, athletes who reported enjoying their sport experience, who felt capable about their physical skills, and who perceived that their parents were supportive of their sport involvement also reported being more determined to continue playing sport in the future.

In contrast, athletes who reported that they did not enjoy sport, that they doubted their sport ability, and that they felt a lack of parental support tended to report a weaker desire to keep playing sport. A regression analysis was conducted to determine the relative contribution that sport enjoyment, perceptions of physical ability, sport friendship quality, and parental encouragement would make toward predicting commitment. Sport enjoyment contributed to the prediction of sport commitment by accounting for $43 \%$ of the variance associated with sport commitment. Perceived physical ability contributed an additional $2 \%$, but this contribution only approached significance $(p<.07)$. The regression equation standardized beta weights for sport enjoyment $(\beta=.56)$ and perceptions of physical ability $(\beta$ $=.13)$ and positive aspects of sport friendship quality $(\beta=.13)$ indicate the relative importance of these variables compared to the negative aspects of sport friendship quality $(\beta=-.02)$ and parental encouragement $(\beta=-.01)$.

The regression equation and correlations make it clear that sport enjoyment, and to a much lesser degree perceptions of physical ability, are most strongly related to athletes' desires to keep participating in disability sport in the future. The relationship between sport enjoyment and sport commitment has been a consistent finding in research (Brustad, Babkes, \& Smith, 2001; Scanlan \& Lewthwaite, 1986; Scanlan, Stein, \& Ravizza, 1989), examining children and adolescents without disabilities; the current study adds to the generalizability of those findings. Although parental encouragement and positive aspects of friendship quality were somewhat correlated with sport commitment, they didn't enter the regression equation and add any predictive value. The negative aspect of sport friendship quality was unrelated to all other variables.

Clearly, the psychological variables of sport enjoyment and perceptions of physical ability were more important compared to the socialization variables of parental encouragement and sport friendship quality. This pattern suggests that the 
positive affective experience (i.e., enjoyment) derived from participating in disability sport, and to a far lesser degree feelings of sport mastery, are much more critical to developing sport commitment compared to parental support or the varied benefits (see Weiss \& Smith, 1999) derived from sport friendship.

The average age of the athletes participating in this study was approximately fifteen. According to Coakley (2001), preadolescence (10-13 years of age) is the developmental stage in which peers and friends are most critical. Additionally, parental influence has likely diminished by this age (Fredricks \& Eccles, 2004). It is plausible that the failure to support socialization variables, particularly parental encouragement, is partially reflective of the developmental stage of participants. It is also reasonable to expect that many of the athletes' best friends on the team were not their "true best friend" when considering their friends from outside of sport. A more comprehensive measure of the motivational properties of being with peers in sport would likely allow participants to reflect on all of their teammates.

A few more limitations warrant comment. Data were collected via self-report measures, which are sometimes susceptible to social desirability (Crowne \& Marlowe, 1960). Confidence in the current findings would certainly be bolstered if future researchers assessed parental and peer perceptions of encouragement and friendship, respectively. Additionally, the self-report nature of the scales may have contributed to shared method variance (Lindell \& Whitney, 2001).

As with all correlational designs, the findings preclude establishing cause and effect relationships. However, the relationships among sport enjoyment, perceptions of physical ability, and sport commitment are supportive of both potential causal mechanisms and reciprocal pathways. For instance, perceptions of competence about one's physical ability can lead to positive affect such as enjoyment (Brustad, Babkes, \& Smith, 2001), and enjoyment can motivate athletes to continue to seek out sport opportunities (i.e., increase commitment) to experience (Scanlan \& Lewthwaite, 1986; Scanlan, Stein, \& Ravizza, 1989).

In conclusion, the present investigation was an initial step toward addressing a lack of research examining disability youth sport from a psychosocial perspective. Two important findings warrant highlighting. First, youth athletes with disabilities reported that their sport experience, as reflected by the motivational, affective, cognitive, and social variables assessed, was a positive one. Second, sport enjoyment was strongly predictive of sport commitment indicating its potentially valuable role in helping youth with disabilities maintain their desire to remain in sport.

\section{References}

Bandura, A. (1997). Self-efficacy: The exercise of control. New York: W.H. Freeman.

Brustad, R.J. (1996). Attraction to physical activity in urban schoolchildren: Parental socialization and gender influences. Research Quarterly for Exercise and Sport, 67, 316-323.

Brustad, R.J. (1993). Who will go out and play? Parental and psychological influences on children's attraction to physical activity. Pediatric Exercise Science, 5, 210-223.

Brustad, R.J. (1992). Integrating socialization influences into the study of children's motivation in sport. Journal of Sport and Exercise Psychology, 14, 59-77.

Brustad, R.J., Babkes, M.L., \& Smith, A.L. (2001). Youth in sport: Psychological considerations. In R.N. Singer, H.A. Hausenblas., \& C.M. Janelle. (Eds.), Handbook of sport psychology (2nd ed.; pp.604-635). New York: John Wiley \& Sons. 
Carpenter, P.J., Scanlan, T.K., Simons, J.P., \& Lobel, M. (1993). A test of the sport commitment model using structural equation modeling. Journal of Sport and Exercise Psychology, 15, 119-133.

Chase, M.A., \& Dummer, G.M. (1992). The role of sports as a social status determinant for children. Research Quarterly for Exercise and Sport, 63, 418-424.

Coakley, J. (2001). Sport in society: Issues and controversies (7th ed.). New York: McGraw Hill.

Cohen, J. (1988). Statistical power analysis of the behavioral sciences (2nd ed.). New York: Academic Press.

Cronbach, L.J. (1951). Coefficient alpha and the internal structure of tests. Psychometrika, 16, 296-334.

Crowne, D.P., \& Marlowe, D. (1960). A new scale of social desirability independent of psychopathology. Journal of Consulting Psychology, 24, 349-354.

Dummer, G. (1999). Classification of swimmers with physical disabilities. Adapted Physical Activity Quarterly, 16, 216-218.

Eccles, J.E., \& Harold, R.D. (1991). Gender differences in sport involvement: Applying the Eccles expectancy-value model. Journal of Applied Sport Psychology, 3, 7-35.

(Eccles) Parsons, J.E., Adler, T.F., \& Kaczala, C.M. (1982). Socialization of achievement attitudes and beliefs: Parental influences. Child Development, 53, 310-321.

Evans, J., \& Roberts, G.C. (1987). Physical competence and the development of children's peer relations. Quest, 39, 23-35.

Fredricks, J.A., \& Eccles, J.S. (2004). Parental influences on youth involvement in sports. In M.R. Weiss (Ed.), Developmental sport and exercise psychology: A lifespan perspective (pp.145-164). Morgantown, WV: Fitness Information Technology.

Gill, D.L., Gross, J.B., \& Huddleston, S. (1985). Participation motivation in youth sports. International Journal of Sport Psychology, 14, 1-14.

Gould, D., Feltz, D., \& Weiss, M. (1985). Motives for competing in competitive youth swimming. International Journal of Sport Psychology, 16, 126-140.

Harter, S. (1982). The perceived competence scale for children. Child Development, 53, 87-97.

Heath, G.W., \& Fentem, P.H. (1997). Physical activity among persons with disabilities - A public health perspective. Exercise and Sport Science Reviews, 25, 195-234.

Horn, T.S. (2004). Developmental perspectives on self-perceptions in children and adolescents. In M.R. Weiss (Ed.), Developmental sport and exercise psychology: A lifespan perspective (pp.101-144). Morgantown, WV: Fitness Information Technology.

Lindell, M. K., \& Whitney, D. J. (2001). Accounting for common method variance in crosssectional research designs. Journal of Applied Psychology, 86, 114-121.

Mandich, A.D., Polatajko, H.J., \& Rodger, S. (2003). Rites of passage: Understanding participation of children with developmental coordination disorder. Human Movement Science, 22, 583-595.

Marsh, H.W. (1990). Self-Description Questionnaire I: Manual. Campbelltown, Australia: University of Western Sydney, Macarthur, Publication Unit, Faculty of Education.

Marsh, H.W. (1987). The Big-Fish-Little-Pond-Effect on academic self-concept. Journal of Educational Psychology, 79, 280-295.

Marsh, H.W. (1993). The multidimensional structure of physical fitness: Invariance over gender and age. Research Quarterly for Exercise and Sport, 64, 256-273.

Marsh, H.W. (1998). Age and gender effects in physical self-concepts of adolescent elite athletes and nonathletes: A multicohort-multioccasion design. Journal of Sport and Exercise Psychology, 20, 237-259.

Marsh, H.W., \& Peart, N. (1988). Competitive and cooperative physical fitness training programs for girls: Effects on physical fitness and on multidimensional self-concepts. Journal of Sport and Exercise Psychology, 10, 390-407. 
Marsh, H.W., Perry, C., Horsely, C., \& Roche, L. (1995). Multidimensional self-concepts of elite athletes: How do they differ from the general population? Journal of Sport and Exercise Psychology, 16, 43-55.

Martin, J.J., \& Mushett, A.C. (1996). Social support mechanisms among athletes with disabilities. Adapted Physical Activity Quarterly, 13, 74-83.

Martin, J.J., \& Smith, K. (2002). Friendship quality in youth disability sport: Perceptions of a best friend. Adapted Physical Activity Quarterly, 19, 472-482.

McNeil, J.M. (1993). Americans with disabilities: 1991-92 (U. S. Bureau of the Census, current population reports, P70-33). Washington, DC: U. S. Government Printing Office.

Messner, M.A. (1992). Power at play: Sports and the problem of masculinity. Boston: Beacon Press.

Nixon, H. (1988). Getting over the worry hurdle: Parental encouragement and the sports involvement of visually impaired children and youth. Adapted Physical Activity Quarterly, 5, 29-43.

Nunnally, J.C. (1978). Psychometric theory (2nd ed.). New York: McGraw Hill.

Parker, J.G., \& Asher, S.R. (1987). Peer relations and later social adjustment: Are lowaccepted children at risk? Psychological Bulletin, 102, 357-389.

Rejeski, W.J., Brawley, L.R., \& Shumaker, S.A. (1996). Physical activity and health related quality of life. Exercise and Sport Science Reviews, 24, 71-108.

Rimmer, J.H., \& Braddock, D. (1997). Physical activity, disability, and cardiovascular health. In A. S. Leon (Ed.), Physical activity and cardiovascular health: A national consensus (pp. 236-244). Champaign, IL: Human Kinetics.

Rimmer, J.H., Braddock, D., \& Pitetti, K.H. (1996). Research on physical activity and disability: An emerging national priority. Medicine and Science in Sport and Exercise, 28, 1366-1372.

Rose, B., Larkin, D., \& Berger, B. (1997). Coordination and gender influences on the perceived competence of children. Adapted Physical Activity Quarterly, 14, 210-221.

Scanlan, T.K., \& Lewthwaite, R. (1986). Social psychological aspects of the competitive sport experience for male youth sport participants: IV. Predictors of enjoyment. Journal of Sport and Exercise Psychology, 8, 25-35.

Scanlan, T.K., Carpenter, P.J., Simons, J.P., Schmidt, G.W., \& Keeler, B. (1993a). An introduction to the sport commitment model. Journal of Sport and Exercise Psychology, 15, 1-15.

Scanlan, T.K., Simons, J.P., Carpenter, P.J., Schmidt, G.W., \& Keeler, B. (1993b). The sport commitment model: Measurement development for the youth sport domain. Journal of Sport and Exercise Psychology, 15, 16-38.

Scanlan, T.K., Stein, G.L., \& Ravizza, K. (1989). An in-depth study of former elite figure skaters: 2. Sources of enjoyment. Journal of Sport and Exercise Psychology, 11, 65-83.

Schoemaker, M.M., \& Kalverboer, A.F. (1994). Social and affective problems of children who are clumsy: How early do they begin? Adapted Physical Activity Quarterly, 11, 130-140.

Sherrill, C. (1997). Disability sport and classification theory: A new era. Adapted Physical Activity Quarterly, 16, 206-215.

Sigelman, C.K., Miller, T.E., \& Whitworth, L.A. (1986). The early development of stigmatizing reactions to physical differences. Journal of Applied Developmental Psychology, 7, 17-32.

Smith, A.L. (1999). Perceptions of peer relationships and physical activity participation in early adolescence. Journal of Sport and Exercise Psychology, 21, 329-350.

Sullivan, H.S. (1953). The interpersonal theory of psychiatry. New York: Norton.

Tabachnick, B.G., \& Fidell, L.S. (1989). Using multivariate statistics (2nd ed). New York: Harper Collins. 
Wang, W., \& DePauw, K.P. (1995). Early sport socialization of elite Chinese athletes with physical and sensory disabilities. Palaestra, 11, 40-46.

Weiss, M.R., \& Chaumeton, N. (1992). Motivational orientations in sport. In T.S. Horn (Ed.), Advances in sport psychology, (2nd ed., pp. 61-99). Champaign, IL: Human Kinetics.

Weiss, M.R., \& Duncan, S.C. (1992). The relationship between physical competence and peer acceptance in the context of children's sport participation. Journal of Sport and Exercise Psychology, 14, 177-191.

Weiss, M.R., \& Ferrer-Caja, E. (2002). Motivational orientations and sport behavior. In T.S. Horn (Ed.), Advances in sport psychology, (2nd ed., pp. 101-184). Champaign, IL: Human Kinetics.

Weiss, M. R., \& Smith, A. L. (1999). Quality of youth sport friendships: Measurement and validation. Journal of Sport and Exercise Psychology, 21, 145-166.

Weiss, M.R., \& Stuntz, C.P. (2004). A little friendly competition: Peer relationships and psychosocial development in youth sport and physical activity contexts. In M.R. Weiss (Ed.), Developmental sport and exercise psychology: A lifespan perspective. (pp. 165198). Morgantown, WV: Fitness Information Technology.

Weiss, M.R., Smith, A.L., \& Theeboom, M. (1996). "That's what friends are for": Children's and teenagers' perceptions of peer relationships in the sport domain. Journal of Sport and Exercise Psychology, 18, 347-379.

Whitehead, J.R., \& Corbin, C.B. (1997). Self-esteem in children and youth: The role of sport and physical education. In K.R. Fox (Ed.), The physical self: From motivation to well being. (pp. 175-204). Champaign, IL: Human Kinetics. 